\title{
A IMPORTÂNCIA DA ENCICLOPÉDIA JURÍDICA NA FORMAÇÃO DO JURISTA
}

\author{
Humberto Grande \\ Professor Catedrático da Faculdade de \\ Direito da Universidade do Paraná \\ $-\mathrm{I}-$
}

A idéia de enciclopédia é muito rica e fecunda e por isso mesmo complexa e difícil, razão porque, por vêzes, perde o seu prestígio, mas sempre renasce forte e exuberante nos períodos de síntese.

Convencem-nos da realidade dessa afirmativa os exemplos históricos. Podemos considerar as obras de Aristóteles como a enciclopédia da cultura grega; o Corpus Juris Civile como enciclopédia romana; a Summa Theologica de Santo Tomaz de Aquino como a enciclopédia medieválica; a enciclopédia de Diderot e D'Alembert, mas conhecida por Enciclopédia francesa, como a enciclopédia moderna; a Enciclopédia Britânica já é o tipo da enciclopédia contemporânea, e de futuro, podemos pensar na possibilidade da organização da Enciclopédia Mundial.

Bastam êsses fatos para demonstrar a fecundidade do princípio, que sempre atuou na esfera do direito.

A história da Enciclopédia Jurídica revela-nos que ela se firmou como disciplina autônoma no século XVII, quando tomou as acepções do pensamento da época, o que sempre sucederá no futuro. Tornou-se racionalista no século XVIII, empirista no século XIX e agora se encaminha francamente para novos horizontes. 
Eis o que nos importa. O conceito de enciclopédia está sempre em contínua evolução. Foi o que nos mostrou D'Alembert no seu magistral "Discurso preliminar da Enciclopédia", afirmando: "A obra que começamos - e que desejamos terminar - tem dois objetos: como enciclopédia deve expor, no possível, a ordem e o encadeamento dos conhecimentos humanos; como dicionário raciocinado das ciências, das artes e dos ofícios, conterá sôbre cada ciência e sôbre cada arte, seja liberal ou mecânica, os princípios gerais que constituem a sua base e os pormenores mais essenciais que formam o seu corpo e a sua substância. Estes dois pontos de vista, de enciclopédia e de dicionário raciocinado, formarão, pois, o plano e a divisão do nosso Discurso Preliminar. Vamos considerá-los sucessivamente e dar conta dos meios pelos quais se intentou conseguir êsse duplo objeto.

Por pouco que se haja refletido sôbre o enlace que os descobrimentos tem entre si, é fácil reparar que as ciências e as artes prestam-se ajuda mùtuamente, e que existe, por conseguinte, uma cadeia que as une. Mas se, em geral, oferece bastante dificuldade reduzir a um pequeno número de regras ou de noções gerais cada ciência ou cada arte em particular, não é mais fácil encerrar num sistema mesmo os ramos infinitamente variados da ciência humana.

O primeiro passo que temos de dar nesta investigação é o de examinar, permita-se-nos a expressão, a genealogia e a filiação dos nossos conhecimentos, as causas a que devem o seu nascimento e os caracteres que as distinguem; numa palavra, o de remontar até a origem e a germinação das nossas idéias. Independentemente da ajuda que haja de proporcionar-nos êste exame para a enumeração enciclopédica das ciências e das artes, tem, sem dúvida, o seu adequado lugar na cabeça de um dicionário raciocinado dos conhecimentos humanos".

Em certos períodos, a literatura enciclopédica cresce extraordinàriamente, como aconteceu na Alemanha, sob o influxo de Shelling e Hegel, quando apareceram as obras de Putter, Falla, Fredlander, Ahrens, Walter, Goldschmidt e tantos outros. Mas súbito as cousas mudam, e chega-se a falar na esterilidade do próprio princípio, o que foi sustentado principalmente por espíritos limitados e superficiais. 
A Enciclopédia Jurídica tem, entretanto, muito futuro, mesmo porque ela nos conduz necessàriamente ao estudo da Filosofia do Direito. Picard escreveu: "Viver sem um Sistema na esfera do Direito, não é viver uma vida de Jurisconsulto".

A Enciclopédia faz, por seus trabalhos, parecer o Direito mais concentrado, mais condensado, mais intenso que aparece na realidade velada, e produz assim em todos os homens de Direito uma vida jurídica mais ardente e melhor ordenada. Ela evita a dispersão das noções jurídicas. Ela cria, para o Direito, uma fisionomia de conjunto. É $A$ GRANDE CIDADE JURIDICA, a Acrópole jurídica, a High-life jurídica. Sem as suas vistas dominadoras, "zodiacais", não se é um "gentleman jurídico".

Tôdas essas considerações têm um objetivo pedagógico. O ensino do direito deve ser uma cousa viva, animada e interessante, para despertar entusiasmo, dedicação e vontade forte do aluno.

Cumpre assim situar o direito na época atual, na vida social ambiente e local.

Animá-lo com os acontecimentos, fatos e realidades da vida e da cultura. Torná-lo interessante através das suas soluções, dos seus problemas e casos. O estudo do direito é apaixonante. Em magistral trabalho sôbre - O PROBLEMA DA SERIAÇÃO DO ENSINO JURÍDICO, o Professor Francisco de A. Figueira de Mello, de acôrdo principalmente com os autores alemães, pondera: "Ao lado da cultura geral, intervém a cultura profissional, orientada pelos deveres que incumbirão aos juristas na vida prática.

Zittelmann aponta dois requisitos básicos.

O jurista deve conhecer os casos reais da vida que êle tenha de decidir de acôrdo com o direito, o que importa proclamar não se reduzir a sua atividade a um simples raciocínio lógico.

O jurista necessita conhecer o direito a aplicar, o que não significa dever êle ter de memória tôda a legislação vigente - fato tão impossível quanto inútil, dada a possibili- 
dade de, quando preciso, verificar os textos legais; - basta que o jurista, além de dominar o conjunto do sistema jurídico e de apreender a relação dos seus institutos de modo a orientar-se sempre com segurança, possua a faculdade de compreender a norma jurídica e de desenvolver-lhe o conteúdo.

Em resumo: "O que o jurista deve adquirir pelo estudo teórico é, não tanto um conhecimento de memória quanto, antes de tudo, uma educação intelectual - como disse uma vez um jurista inglês: "not information, but formation of mind", uma educação que o habilite a ver acertadamente a realidade e uma educação do pensar jurídico próprio. Simultâneamente precisa êle possuir, também, uma visão geral das correlações e da conjunção da massa imensa do direito e da realidade".

A personalidade do jurista desenvolve-se na vida jurídica, em contato com os problemas e as suas soluções.

$E$ preciso enriquecer o direito com as mais recentes conquistas culturais, para termos um direito atualizado, à altura dos tempos.

Neste sentido, a enciclopédia jurídica é utilíssima. O seu estudo tem valor pedagógico, pelo caráter objetivo, concreto e real dos seus ensinamentos. O aluno defronta-se desde logo com o direito nas suas mais variadas manifestações. Aprende assim a universalidade do fenômeno jurídico, que regula as relações individuais, nacionais e internacionais.

Essa visão panorâmica estimula a curiosidade do jovem e aumenta a sua vontade de conhecer.

A enciclopédia jurídica é útil como introdução e como conclusão dos estudos jurídicos. Ela pode traduzir-se para os juristas em qualquer momento num balanço do que cada um sabe sôbre o direito.

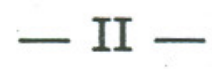

A enciclopédia jurídica dá largueza de visão ao jurista. Ela repousa a sua mente, renova as suas idéias e estimula o seu trabalho.

Todo jurista, digno dêsse nome, deve cultivá-la com ardor e entusiasmo. Não basta sentir o direito na esfera res- 
trita de uma especialidade. É mister compreendê-lo no seu todo, em plena pujança do seu ser.

Por isso o aluno não deve abandonar o estudo da enciclopédia jurídica logo ao concluir o primeiro ano do seu curso, ou então, ao diplomar-se.

Seria êrro gravíssimo tal procedimento. A enciclopédia jurídica deve ser a preocupação permanente da sua vida. Ela não é só uma disciplina propedêutica e auxiliar, mas é também uma disciplina complementar e altamente cultural. Como afirma Filomusi Guelfi: "O princípio, portanto, é 'idêntico ao fim. Parte-se da Enciclopédia como ciência de introdução para retornar à Enciclopédia como ciência final".

O verdadeiro jurista necessita muito do espírito enciclopédico, que, aliás, sempre desempenha grande papel na fase sintética da cultura. A respeito dêsse assunto, Alexis Carrel faz as seguintes observações, que devem ser meditadas longamente pelos homens cultos: "A sociedade precisa de super-homens, uma vez que não é capaz de se dirigir, e uma vez que a civilização do Ocidente foi abalada até os seus alicerces.

Para alcançar êsse resultado, não são necessárias nem habitações imponentes, nem grandes somas de dinheiro, nem burocracia. Bastam pequenas unidades, independentes umas das outras, e administrando-se por si próprias. Dêsse modo, a organização duma nova unidade, ou a desorganização duma antiga, não terão qualquer efeito sôbre as outras. Os edifícios simples e de pouco custo serão construídos em função dum dado problema e sem a preocupação de beleza arquitetural. A substância dêsse instituto será a matéria cerebral dum pequeno grupo de homens consagrados ao complexo problema cuja solução constitui finalidade para essa emprêsa. A função essencial dêsse grupo será orientar as investigações na direção desejada e assegurar a sua continuidade que certas experiências feitas em sêres humanos deverão prolongar-se por mais de um século. O caráter sintético dêsse trabalho exige que a sua direção não vá parar às mãos de especialistas da biologia, da psicologia, ou de qualquer outra ciência. Só homens de inteligência amplamente compreensiva e libertos de qualquer doutrina ou preconceito serão capazes de encarar os problemas fisiológicos e mentais, sob um 
ponto de vista verdadeiramente humano. Decerto que ao lado dêsses homens, será necessária a presença de especialistas. E felizmente que existem muitos e excelentes especialistas. Os espíritos não especializados e de tendências sintéticas é que são raros. E, no entanto, o seu papel é de capital importância na diretoria dum centro de investigações. Não devemos esquecer que o Instituto Kaiser Wilhelm se desenvolveu de modo admirável sob a orientação dum teólogo de larga inteligência, Adolfo von Harneck. O êxito do Instituto Rockfeller deve-se a Simon Flexner, que abandonou as suas especiais investigações, para se interessar por tôdas as ciências. Ültimamente, a Fundação Rockfeller julgou oportuno pôr à sua frente, não um sábio, mas um homem de leis, com espírito capaz de abranger os mais variados assuntos. Homens dêsse tipo intelectual é que serão a alma do novo centro de investigações".

Vemos aí o reconhecimento autorizado do valor do espírito enciclopédico na formação do jurista. O enciclopedismo representa, na esfera da cultura, enérgica reação contra a unilateralidade, dispersão e análise exagerada. O objetivo da enciclopédia jurídica é oferecer uma visão de todo o conjunto do império jurídico, uma imagem sensível da grandeza do direito.

No meu estudo sôbre "A COMPREENSÃO DO DIREITO", afirmei convictamente: "É pedagógico incutir no aluno elevado sentimento do direito. Por isso mesmo doutrinamos a sua grandeza, para restabelecer plenamente o seu valor nesta época trágica, de lutas, revoluções e guerras, quando só se fala em crise, declínio, decadência e morte do direito. A grandeza constitui a dimensão própria do espírito, que, alado como é, através dela, voa alto. Êste conceito provoca reações, movimentos diversos, fortes tensões e polarizações fecundas, porque integra a realidade nas suas verdadeiras proporções. Assim alarga qualquer assunto, rasga amplos horizontes, renova e cria valor.

Tal noção ajuda muito a compreensão do direito, e é universal pela sua própria natureza, regulando as relações de tôdas as coisas na terra, como no mar e no ar, quer sejam públicas ou privadas. 
Para uma visão global do direito privado, convém precisar as noções da vida civil e comercial, da agricultura, indústria e comércio, do mar e do ar, pois, êsses elementos são a alma do direito civil, do direito comercial, do direito marítimo, do direito industrial e do direito aéreo. Mas o direito privado está se desenvolvendo em outros ramos, alargando a sua esfera de abrangência em crescente especialização, como agora já observamos no direito cambiário, no direito de transporte, no direito radiofônico, ferroviário, cinematográfico, etc.

O mesmo acontece no direito público. Faz-se mister, preliminarmente, precisar os conceitos de constituição, administração, processo, pena, trabalho e comunidade internacional, que originam, respectivamente, o direito constitucional, o direito administrativo, o direito processual, o direito penal, o direito do trabalho e o direito público internacional.

O verdadeiro jurista deve ter a compreensão total do direito através da enciclopédia jurídica. Ninguém pode compreendê-lo através sòmente da especialização.

$\mathrm{Na}$ época atual, é necessário insistir neste particular. O direito especializou-se ao máximo. Desenvolveu-se em vários novos ramos, e a especialização continua com intensidade. Mas essa tendência tem um lado negativo. O jurista excessivamente especializado não entende mais o direito, porque embora conheça bem o seu setor, ignora 0 resto.

Para garantir os progressos do direito, cumpre unificálo e reconstituir o seu todo num conjunto vivo e animado.

Nunca nos devemos esquecer que o direito é uma ciência prática, o que, infelizmente, acontece com os professôres, juristas de gabinete e teóricos de todo gênero. O que dizia Alexis Carrel da antropologia aplica-se também ao direito: "O número imenso de dados que possuímos hoje sôbre o homem é um obstáculo ao seu emprêgo. Para ser utilizável o nosso conhecimento deve ser sintético e breve". Eis aí séria advertência aos eruditos do direito, que gostam de redigir grossos tratados e acumular um saber disperso, mesmo que não fecundem o seu próprio pensamento.

O especialista exagerado é desumano, e Ortega y Gasset 
fala-nos com muita propriedade da barbaria do especialismo. Diz êle: "O especialista "sabe" muito bem o seu mínimo rincão de universo, mas ignora radicalmente todo o resto". E continua: "Não é um sábio, porque ignora formalmente quando não entra na sua especialidade; porém tão pouco é um ignorante, porque é "um homem de ciência" e conhece muito bem a sua porciúncula de universo. Teremos de dizer que é um sábio-ignorante, coisa sobremaneira grave, pois significa que é um senhor o qual se comportará em tôdas as questões que ignora, não como ignorante, mas com tôda petulância de quem na sua questão especial é um sábio".

Mas se o especialismo é unilateral, o enciclopedismo também tem o perigo da superficialidade. Cumpre na cultura combinar essas duas tendências em dosagem proporcional, conhecendo o todo para entender a parte. Como diz Goethe: "Havia aprendido algo, porém êste algo só servia para fazerme crer que nada sabia, e tinha razão: faltava-me a compreensão do conjunto, da qual dependem todos os conhecimentos humanos". O grande poeta e sábio alemão acentua ainda: "Em realidade, só sabemos algo, se sabemos pouco. Enquanto as nossas noções aumentam, surgem pouco a pouco as dúvidas". Dai a modéstia de Sócrates quando declarava que só sabia uma coisa. É que nada sabia.

O estudo criterioso do direito exige tôdas estás precauções. O fenômeno jurídico é uma realidade complexa, múltipla, variada e polifacética, que encerra o real e o ideal, combina o material com o espiritual, o físico com o mental. Precisamos compreendê-lo tal como êle é. Simplificá-lo, muitas vêzes, é diminuí-lo, reduzí-lo e amputá-lo.

Assim a compreensão do direito não é fácil. Exige a compreensão da época, a compreensão da vida e a compreensão da cultura.

Para estar à altura do direito, ao jurista não lhe bastam a cultura livresca, a erudição, a leitura dos tratados, as notas, os apontamentos e as informações. Não. Precisa viver o direito nas suas diversas manifestações. Vivê-lo aqui significa recriá-lo, aplicá-lo, realizá-lo, adquirindo diretamente muita experiência jurídica.

Dentro dêsse programa de estudo, o jurista só atinge a 
plenitude da sua árdua profissão, quando lhe chegam os cabelos brancos, e quando através da sua vivência jurídica, já conhece a vida, os homens e as coisas. E assim mesmo é obrigado a continuar estudando, cada vez mais com maior ardor, para poder pelo direito alcançar a justiça.

Levam-nos, agora, essas conclusões a estudar as relações entre o espírito enciclopédico e a cultura na esfera do direito, o que faremos dentro da nossa concepção jurídica.

\section{- III -}

A enciclopédia jurídica é vasto campo de cultura do direito, onde podemos sempre captar novos valores.

Ela assim enriquece o direito com valiosas contribuições e permite-lhe realizar, com maior soma de recursos, a sua grande missão.

O pensamento jurídico deve desenvolver-se nesta ampla esfera, para vencer as limitações de uma especialidade, que quando não sai do seu círculo, diminui e empequenece o sentido das cousas.

O verdadeiro sentido está na correlação entre a parte e o todo, e principalmente em não isolar a parte do todo e não ver o todo sem as partes.

A tendência do especialista é desligar a parte. Analisála ao extremo. Decompô-la até que fique reduzida a nada, quando, então, se dissipa o seu sentido.

Foi o que hodiernamente aconteceu com o direito, em virtude de especialização exagerada. Cada especialista sòmente o enxerga no seu setor e não o compreende no seu todo.

Para vitalizar o direito, os juristas precisam entendê-lo na sua integralidade, que é onde reside a sua profunda significação.

Quando ao direito lhe falta o sentido, o indivíduo fica sem a liberdade e a sociedade, sem a organização.

$\mathrm{O}$ direito transforma-se em coisa, meio e mera instrumentalidade, desaparecendo a sua identidade, o seu caráter, a sua natureza e o seu valor. 
Quando o direito não encontra o sentido, a humanidade volta para a selvageria e barbaria.

A nossa época ilustrou expressivamente tais afirmações, com os acontecimentos da última guerra e as atrocidades nazistas.

A enciclopédia jurídica tem, pois, alta significação cultural. Evidentemente, o desejo do sábio, em qualquer setor, é a compreensão total de um assunto.

Isto não é fácil. Mas um espírito aberto e bem orientado muito pode obter.

A compreensão do direito não se limita a um aspecto da sua complicada natureza, mas sim, ao todo. Do contrário, unilateralmente não podemos compreendê-lo.

Eis aí o nosso ponto de vista. A compreensão, quanto mais ampla, mais verdadeira, mais próxima da realidade.

O jurista deve esforçar-se por compreender todo o direito. Eis o objetivo da enciclopédia jurídica.

O direito possui vasto e extenso império. Assim o direito divide o seu império em muitos condados, criando na região em que vive várias mansões e moradas. As instituições, depois de Ulpiano, expressaram, com a maior amplitude, êsse fato, nesta imortal definição: "Jurisprudentia est rerum divinarum atque humanarum notitia, justi atque injusti scientia". E como bem sentiu o grande jurista norte-americano Roscoe Pound: "Completa Ciência do Direito não pode menosprezar a investigação analítica ou filosófica. Cada uma delas é necessária para um efetivo corpo de conhecimentos. $\mathrm{O}$ êrro tem consistido em tomar um aspecto pelo todo... Na casa da Jurisprudência há muitas moradas".

Eis aí nova expressão da grandeza do direito, considerado no seu conjunto, nas suas grandes divisões e nas suas relações.

Já a antiga Roma ministrou-nos o conceito da grandeza imperial do direito, e para os romanos, o direito foi a ciência suprema. Como bem expressou Ihering: "Três vêzes Roma ditou leis ao mundo e serviu de laço de união entre os povos: 
primeiro, pela unidade do Estado romano na plenitude do seu poderio; depois, pela unidade da Igreja na queda do Império; finalmente, pela unidade do direito ao ser adotado o de Roma na Idade Média. A importância e missão de Roma na história resume-se em que representa o triunfo da idéia da universalidade sôbre o princípio das nacionalidades. Os males sofridos pelos povos debaixo das cadeias romanas trocaram-se em vantagens para a história e para os povos. Graças a Roma foi restaurada a unidade do antigo mundo; por haver-se reunido em Roma os filhos da velha civilização foi possível a nova civilização cristã. Sem o centralismo da Roma pagã não haveria nascido a Roma cristã.

Durante a segunda dominação universal de Roma, os povos receberam a sua educação moral e religiosa e quando, pela terceira vez, as novas gerações buscaram as suas leis, foi Roma antiga que lhas deu. Um direito morto, escrito numa língua que só os sábios entendiam, combatido por mil resistências, impõe-se e triunfa. Foi depois de morta, quase aniquilada a sua autoridade, quando Roma triunfou plenamente e o seu código de leis cobrou uma perfeitíssima forma que se converteu na regra do nosso pensamento jurídico. A importância do Direito romano para o mundo atual não reside em haver sido fonte e origem do direito, senão na transformação que imprimiu ao nosso pensamento jurídico e em haver-se convertido, como o cristianismo, em elemento da civilização moderna. Talvez os dois períodos anteriores oferecem um espetáculo mais interessante, porém a difusão e predomínio do Direito romano no mundo moderno é um dos fenômenos mais maravilhosos da história e dos triunfos mais extraordinários da fôrça intelectual".

Eis a grandeza imperial do direito na concepção romana, grandeza, ao mesmo tempo, histórica, filosófica e cultural. Precisamos saber penetrar nesse formidável império, para nêle gozar dos direitos de cidadania.

Roma caput mundis, Roma princeps urbium, Roma a Cidade Eterna deu-nos uma grande lição de direito, de ordem e organização; uma lição de paz, realismo e senso prático. $\mathrm{O}$ nosso mundo conturbado conquistaria a tranquilidade e equilíbrio se soubesse reviver a gloriosa PAX ROMANA. 
"Mas tu, ó romanю, tens de governar os povos

Tua arte é ensinar os caminhos da paz,

Poupar aos humildes e derrubar os orgulhosos"

(Eneida, Vergílio)

O mundo, agora, mais do que nunca precisa do jurista, porque como escreveu Ripert: "A obra do jurista é a única que fica quando o tumulto das revoluções se aplaca". Mas o jurista deve estar à altura dos tempos, da sua nobre missão e das suas grandes responsabilidades. Precisa possuir por isso mesmo cultura moderna, atualizada e muito ativa.

O jovem jurista, principalmente, deve sentir a majestade da sua carreira. O direito é universal. Abrange tôdas as cousas. Está sempre ampliando a sua esfera ao regular novas relações jurídicas, ao criar novos ramos e ao apresentar novas instituições.

O verdadeiro jurista deve tudo fazer para fortalecer o império do direito no mundo, porque êsse império grandioso é o império da dignidade e do respeito, o império da disciplina e da liberdade, o império da ordem e do progresso, o império do trabalho e da produção, o império da lei e da justiça, enfim, é o império da paz e da harmonia. 